\title{
Rangeland management under uncertainty: A conceptual approach
}

\author{
AMITRAJEET A. BATABYAL AND E. BRUCE GODFREY
}

Authors are Arthur J. Gosnell Professor, Economics Department, Rochester Institute of Technology, Rochester, New York 14623-5604, and Professor, Economics Department, Utah State University, Logan, Ut. 84322-3530. At the time of the research, the senior author was Associate Professor, Economics Department, Utah State University, Logan, Ut.

\begin{abstract}
A conceptual approach is commonly needed to provide guidance for developing new strategies concerning the use and management of renewable resources such as rangelands. The theoretical model constructed in this paper captures the essential aspects of dynamic and stochastic issues associated with the management of rangelands. We discuss the connections between the model and range policy. Specifically, we point out scenarios in which there is a limited role for policy. This is compared to scenarios when policy has a significant role to play in ensuring the sustainable use of rangelands. Finally, we suggest 2 ways in which our approach might be extended and used in a practical application.
\end{abstract}

Key Words: dynamic, policy, resource, stochastic

Rangelands are an important renewable resource. In addition to performing a number of salient ecological functions, rangelands provide humans with consumable products such as red meat, fiber and water, and non-consumptive services such as recreation and wildlife viewing. As such, it is no surprise that range managers have systematically attempted to manipulate "range components to obtain the optimum combination of goods and services for society on a sustained basis" (Holechek et al. 2001, p. 5). The management of rangelands is not easy because range managers rarely have complete information about the impact of actions that may be taken. This state of affairs is in part due to a lacuna in the range management literature. Although previous studies (Lambert and Harris 1990, Passmore and Brown 1991, McCluskey and Rausser 1999, Batabyal 2000, Batabyal et al. 2001) have studied aspects of range management in the presence of uncertainty, there are very few studies that have explicitly modeled the connections between uncertainty, the ecology, and the management of rangelands over time.

Given this state of affairs, a conceptual approach is needed to provide guidance for developing new strategies concerning policies that affect the use of rangelands. The model outlined below has 3 desirable features. First, the approach is consistent with an important ecological model of range behavior, namely, the stateand-transition model of Westoby et al. (1989). Second, the

\footnotetext{
Research was funded by the Utah Agricultural Experiment Station Project UTA 024 and by the Gosnell Endowment at RIT.

Manuscript accepted 11 Mar. 2001
}

Resumen

Comúnmente se necesita una propuesta conceptual como guía para desarrollar nuevas estrategias concernientes con el uso y manejo de los recursos naturales tales como los pastizales. EI modelo teórico construido en este articulo captura los aspectos esenciales de problemas dinámicos y estocásticos asociados con el manejo de pastizales. Discutimos las conexiones entre el modelo y la política de los pastizales, específicamente puntualizamos escenarios en los cuales hay un papel limitado de esta política $y$ esto es comparado con escenarios en los que la política tiene un papel significativo para asegurar el uso sustentable de los pastizales. Finalmente sugerimos dos formas en las cuales nuestra propuesta pudiera se extendida y utilizada en una aplicación práctica.

approach expressly accounts for the role that uncertainty plays in the temporal evolution of managed rangelands. Finally, by exploring the connections between policy and range behavior, our approach defines the role that policy can play, and, on occasion, not play in ensuring the sustainable use of rangelands. The formal state-and-transition model outlined in the following section provides the basis for a discussion of the policy implications associated with the dynamic and the stochastic structure of rangelands. This discussion is followed by an extension of the model in 2 ways that are likely to be important and that are not captured in the basic model. The final section of the paper outlines areas for future research.

\section{A "State-and-Transition" Model of a Rangeland}

\section{Preliminaries}

As discussed but not formalized in Westoby et al. (1989), rangeland dynamics can be usefully described in terms of a discrete number of states and a set of transitions between these states. Range managers often use the term "condition class" to refer to these states. Moreover, as noted in Holechek et al. (2001), it is common to think of rangelands as existing in 1 of 4 possible condition classes such as excellent, good, fair, and poor. Consequently, we assume that rangelands can exist in 4 possible states, but the number of states could easily be extended, without any loss of generality, to any countable number of states. 
Environmental factors such as fire and/or actions such as the alteration of the stocking rate result in rangeland transitions from 1 condition class to the other. To formalize this notion, suppose that our rangeland makes state transitions in accordance with a discrete-time Markov chain (Ross 1997, Perrings 1998). In other words, when in state $i, i=1, \ldots, 4$, the rangeland will make a transition to state $j$, $j=1, \ldots, 4$, with probability $P_{i j}$. From a management perspective, not all condition classes are equally desirable. In particular, it seems reasonable to think of excellent (state 1) and good (state 2) as constituting the desirable set of states, and fair (state 3) and poor (state 4) constituting the undesirable set of states of the rangeland. Formally, we have $D=\{$ Excellent (state 1), Good (state 2) $\}$, and $U=\{$ Fair (state 3), Poor (state 4)\}.

The goals of resource managers are to use the policies at their disposal (i.e., changing the stocking rate, burning, introducing plant populations) to keep the rangeland in the desirable set $D$ for as long as possible. However, because resource managers cannot be certain about the appropriateness of a particular policy (say, all the positive and negative implications of a burn) and because state transitions occur not only because of managerial actions but also because of environmental factors, it is possible that despite the resource manager's best intentions, the rangeland will end up in a state in the undesirable set $U$. As such, resource managers would like to know 2 things. First, what is the expected amount of time $(U)$ that the rangeland spends in set $U$, given that it is currently in a state in $U$. Second, what is the expected amount of time $(\bar{D})$ the rangeland spends in set $D$, given that it is presently in a state in $D$. Let us now compute these 2 expectations.

\section{Two Expectations}

Let $\pi_{k}, k=1, \ldots, 4$, denote the stationary probabilities (see Ross 1997, pp. 172-182) of the rangeland. Now, for state $i \varepsilon D$ and state $j \varepsilon U$, the rate at which the rangeland enters state $j$ from state $i$ is $\pi_{i} P_{i j}$. From this it follows that the rate at which our rangeland enters state $j$ from a state in the desirable set $D$ is $\sum_{i=1}^{2} \pi_{i} P_{i j}$. With these 2 pieces of information, we conclude that the rate at which our rangeland moves from the desirable to the undesirable set of states is $\sum_{j=3}^{4} \sum_{i=1}^{2} \pi_{i} P_{i j}$. Similarly, but now in terms of the 2 expectations $\bar{D}$ and $\bar{U}$, the rate at which the rangeland moves from the desirable to the undesirable set of states is $1 /(\overline{\mathrm{D}}+\bar{U})$ Equating these last 2 expressions, we get

$$
\sum_{j=3}^{4} \sum_{i=1}^{2} \pi_{i} P_{i j}=\frac{1}{\bar{D}+\bar{U}}
$$

To compute $\bar{D}$ and $\bar{U}$ explicitly, we need a second equation linking these 2 expectations. This equation can be obtained by noting 2 facts. First, the percentage of time that the rangeland is in the desirable set of states is $\sum_{i=1}^{2} \pi_{i}$. Second, the proportion of time the rangeland spends in the desirable set of states is $\bar{D} /(\bar{D}+\bar{U})$. Combining these 2 facts, we get

$$
\sum_{i=1}^{2} \pi_{i}=\frac{\bar{D}}{\bar{D}+\bar{U}}
$$

Now using equations (1) and (2), it is straightforward to verify that

$$
\bar{D}=\frac{\sum_{i=1}^{2} \pi_{i}}{\sum_{j=3}^{4} \sum_{i=1}^{2} \pi_{i} P_{i j}}, \bar{U}=\frac{\sum_{j=3}^{4} \pi_{j}}{\sum_{j=3}^{4} \sum_{i=1}^{2} \pi_{i} P_{i j}}
$$

Inspecting equation (3) and recalling the properties of the stationary probabilities of a Markov chain (Ross 1997), it is clear that although managerial actions can influence the expected amount of time that the rangeland spends in the desirable and the undesirable set of states, ultimately, it is the transition probabilities, i.e., the $\mathrm{P}_{\mathrm{ij}} \mathrm{s}$, that should be the target of range policy. To see this clearly, consider the connections between alternate policies and the transition probability matrix, $P$, of our 4 state rangeland (Markov chain). $P$ can be written as

$$
P=\left[\begin{array}{llll}
P_{11} & P_{12} & P_{13} & P_{14} \\
P_{21} & P_{22} & P_{23} & P_{24} \\
P_{31} & P_{32} & P_{33} & P_{34} \\
P_{41} & P_{42} & P_{43} & P_{44}
\end{array}\right]
$$

In this matrix, the first row and column denote the excellent state (state 1), the second row and column denote the good state (state 2), and so on. Thus, the probability of making a transition to the excellent state (state 1), given that the rangeland is currently in the poor state (state 4), is denoted by $P_{41}$. The other elements of the matrix $P$ have similar interpretations. Now, although resource managers may have disparate policy goals, one reasonable goal is to ensure that the rangeland stays in the desirable set of states $D$, for as long as possible. This can be done by influencing the transition probabilities in the $P$ matrix.

Inspection of equation (4) shows that from the standpoint of range policy, the matrix $P$ can be usefully partitioned into 4 zones. These 4 zones correspond to the following 4 sub-matrices

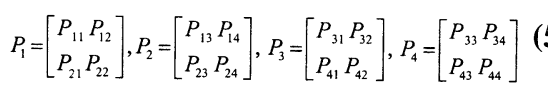

If the rangeland is in $P_{1}$, then it is in the desirable set of states (1 or 2$)$. As such, this is a zone in which no major policy initiatives are required to ensure the wellbeing of this rangeland. In contrast, when the rangeland is in $P_{4}$, it is in the undesirable set of states ( 3 or 4 ) and the probability of bringing it to the desirable set is 0 . This means that in this zone, there is no role for policy. One such "no role" involves taking no action to improve the rangeland. Put differently, the rangeland is so degraded that it is either impractical or actually impossible to restore it to one of the desirable states. The 2 intermediate zones corresponding to $P_{2}$ and $P_{3}$ are of particular interest. This is where there is the greatest scope for policy. In other words, in these 2 zones, resource managers can, inter alia, change the stocking rate, remove noxious plants, keep livestock away from streamside areas, and introduce plant populations, in order to ameliorate the rangeland. Inspecting $P_{2}$, we see that the probabilities here involve moving from the desirable to the undesirable set of states. As such, it is clear that when in this zone, the objective of policy should be to take those actions that will minimize the probabilities in this submatrix and improve the rangeland resource. In contrast, inspection of $P_{3}$ tells us that the probabilities here involve moving from the undesirable to the desirable set of states. This means that when in this zone, policy should confine itself to those actions that maximize the probabilities in this sub-matrix and thereby improve the range. This way of looking at the task of range management provides a clear indication as to when there is a substantial role 
and when there is a very limited role for managerial actions in ensuring the sustainable use of our rangeland. This conceptual approach is now demonstrated with a numerical example.

\section{An Example}

Suppose that the transition probability matrix in equation (4) is

$$
P=\left[\begin{array}{cccc}
1 / 2 & 1 / 2 & 0 & 0 \\
1 / 4 & 1 / 4 & 1 / 4 & 1 / 4 \\
1 / 5 & 1 / 5 & 2 / 5 & 1 / 5 \\
0 & 0 & 1 / 4 & 3 / 4
\end{array}\right]
$$

While the transition probabilities in equation (6) are illustrative, subject to data availability, they can be estimated using econometric techniques (Ethridge et al. 1985). In a practical setting, these probabilities are useful because they provide rangeland managers with information about how the interaction of managerial actions and environmental factors affect range condition. Let us compute $\bar{U}$ and $\bar{D}$. To perform this computation, we shall use a 3-step procedure. First, we observe that the stationary probabilities satisfy $\pi_{1}=$ $(1 / 2) \pi_{1}+(1 / 4) \pi_{2}+(1 / 5) \pi_{3}, \pi_{2}=(1 / 2)$ $\pi_{l}+(1 / 4) \pi_{2}+(1 / 5) \pi_{3}, \pi_{3}=(1 / 4) \pi_{2}+(2 / 5)$ $\pi_{3}+(1 / 4) \pi_{4}$, and $\pi_{4}=1-\sum_{i=1}^{3} \pi_{i}$ (Ross 1997). These 4 equations can be solved to yield $\pi_{1}=4 / 21, \pi_{2}=4 / 21, \pi_{3}=5 / 21$, and $\pi_{4}=8 / 21$. Second, we use these stationary probabilities and the transition probabilities in equation (6) to determine the rate at which our rangeland moves from the desirable to the undesirable set of states, i.e., the denominator of the 2 expressions for $\bar{D}$ and $\bar{U}$ in equation (3). This rate equals $2 / 21$. Finally, we compute $\bar{D}$ and $\bar{U}$ by using this rate $(2 / 21)$, and the expressions in equations (3) and (6). We get $\bar{D}=$ 4 and $\bar{U}=6.5$.

What are the implications of these computations for range policy? These computations tell us that, on average, our rangeland resource moves from the desirable to the undesirable set of states $2 / 21$ or approximately $10 \%$ of the time. The rangeland resource stays in the undesirable set for 6.5 units of time on average. This is followed by a time span, on average 4 units long, during which the rangeland is in the desirable set of states. This kind of rangeland behavior is entirely consistent with the state-and-transition model of Westoby et al. (1989). Further, note that in ecology, the stability concept known as persistence refers to "how long a [resource] lasts before it is changed to a new value" (Pimm 1991, p. 14). In the context of this note, the expectations $\bar{D}$ and $\bar{U}$ can be interpreted as the persistence of, respectively, the desirable and the undesirable set of states. This means that when range use policy is directed to the maximization (minimization) of $\bar{D}(\bar{U})$, society benefits in an economic and in an ecological sense.

\section{Two Extensions}

The discrete-time Markov chain model described above nicely captures the essential elements of dynamic and stochastic rangelands. However, the scope of this model is restricted by the presence of 2 features. First, range policy cannot alter the transition probabilities (the $\mathrm{P}_{i j} \mathrm{~s}$ ) because these probabilities are stationary. Second, range policy also cannot change the amount of time the rangeland spends in a particular state because the discretetime Markov chain spends 1 unit of time in each state before making a transition. How might we account for these 2 features in our model?

First, let us consider the case of non-stationary transition probabilities. In this case, the probability of making a transition from condition class $i$ at time $t-1$ to condition class $j$ at time $t$ depends on $t$. To formalize this time dependence, we write $(t-1, t)$

$P_{i j}^{(t-I, t)}$ instead of $P_{i j}$. Similarly, the transition probability matrix in equation (4) will now have to be replaced by a sequence of transition matrices. In other words, instead of working with the single matrix $\mathrm{P}$ of equation (4), we now work with a sequence of matrices $\left[P_{t}\right]_{t=1}^{\infty}$. Once we specify an initial vector that gives a probability distribution over the states of the non-stationary Markov chain, we have completely described our rangeland. Then we can investigate the limiting behavior of the rangeland under study as time approaches infinity. This rangeland may or may not converge to a limiting vector. For instance, consider the 2-condition class rangeland with transition matrices

$P_{2 t-1}=\left[\begin{array}{cc}1-\frac{1}{2 t-1} & \frac{1}{2 t-1} \\ 1-\frac{1}{2 t-1} & \frac{1}{2 t-1}\end{array}\right], P_{2 t}=\left[\begin{array}{c}\frac{1}{2 t} 1-\frac{1}{2 t} \\ \frac{1}{2 t} 1-\frac{1}{2 t}\end{array}\right], t=1,2,3, \ldots(7)$

In this case, it can be shown, using the methods outlined by Isaacson and Madsen (1976) that this non-stationary Markov chain displays a kind of limiting behavior known as weak ergodicity.

We now address the "unit time in a state before transition" feature. Ideally, we would like rangeland management policy to be conducted in a way that the rangeland resource under study is in the desirable (undesirable) set of states for relatively long (short) periods of time. One way to model this is as follows. We let the transition probabilities be stationary. However, instead of having all transition times be 1 unit long, we now let the amount of time spent in state $i$ before making a transition to state $j$ be a random variable with a general distribution function $F_{i j}(\bullet)$. With this change, we have converted our discretetime Markov chain into a semi-Markov process. We can now investigate the limiting behavior of this semi-Markov process as time approaches infinity by analyzing its embedded Markov chain. Specifically, for a 3-condition class rangeland, if we denote the stationary probabilities of the semi-Markov process by $P_{i}, i=1,2,3$, it can be shown, using the methods outlined by Ross (1997), that these stationary probabilities satisfy $P_{i}=\pi_{i} \mu_{i} / \sum_{j=l}^{3} \pi_{j} \mu_{j} i=1$, 2,3, where $\pi_{i}$ is the embedded Markov chain's stationary probability of being in state $i$ and $\mu_{i}$ is the mean time the semiMarkov process (rangeland) spends in state $i$.

\section{Conclusions}

The conceptual approach presented above highlights the advantages of linking rangeland resource management policy to the dynamic and the stochastic structure of a rangeland. Specifically, our approach is consistent with the state-and-transition model of range behavior proposed by Westoby et al. (1989). This approach explicitly accounts for the fundamental role that uncertainty plays in the temporal evolution of managed rangeland resources. This approach also makes transparent the role that management policy can play, and, on occasion, not play, in ensuring the sustainable use of rangeland resources. Finally, the optimization of management policy objectives $(\bar{D}$ and $\bar{U})$ arising from this approach involves the simultaneous maintenance of ecological stability in the sense of persistence.

The state and transition model can be extended in a number of ways. Transition probabilities are an important component of all the Markov models. Consequently, it would be useful to follow the lead of 
Ethridge et al. (1985) and estimate the transition probabilities of a Markov model of a parcel of rangeland. Knowledge of transition probabilities will enable a researcher to determine the practical merits of stationary versus non-stationary approaches to the study of dynamic and stochastic rangelands.

\section{Literature Cited}

Batabyal, A.A. 2000. An interdisciplinary research agenda for the study of ecologicaleconomic systems in the American West. Resources Policy 26:69-75.
Batabyal, A.A., B. Biswas, and E.B. Godfrey. 2001. The stocking rate versus time in range management: A review of recent theoretical developments. Applied Econ. Letters 8:555559.

Ethridge, D.E., S.K. Roy, and D.W. Myers. 1985. A Markov chain analysis of structural changes in the Texas high plains cotton ginning industry. Southern J. Agr. Econ. 17:11-20.

Holechek, J.L., R.D. Pieper, and C.H. Herbel. 2001. Range management, $4^{\text {th }}$ ed. Englewood Cliffs, N.J.: Prentice Hall.

Isaacson, D.L., and R.W. Madsen. 1976. Markov chains. New York, N.Y.: Wiley.

Lambert, D.K., and T.R. Harris. 1990. Stochastic dynamic optimization and rangeland investment decisions. Western J. Agr. Econ. 15:186-195.
McCluskey, J.J., and G.C. Rausser. 1999. Federal grazing reform and avoidable risk. J. Agr. Resource Econ. 24:140-154

Passmore, G., and C. Brown. 1991. Analysis of rangeland degradation using stochastic dynamic programming. Australian J. Agr. Econ. 35:131-157.

Perrings, C. 1998. Resilience in the dynamics of economy-environment systems. Environ. Resource Econ. 11:503-520.

Pimm, S.L. 1991. The balance of nature? Chicago, Ill.: University of Chicago Press.

Ross, S.M. 1997. Introduction to probability models, $6^{\text {th }}$ ed. San Diego, Cal.: Academic Press.

Westoby, M., B. Walker, and I. Noy_Meir. 1989. Opportunistic management for rangelands not at equilibrium. J. Range Manage. 42:266-274.

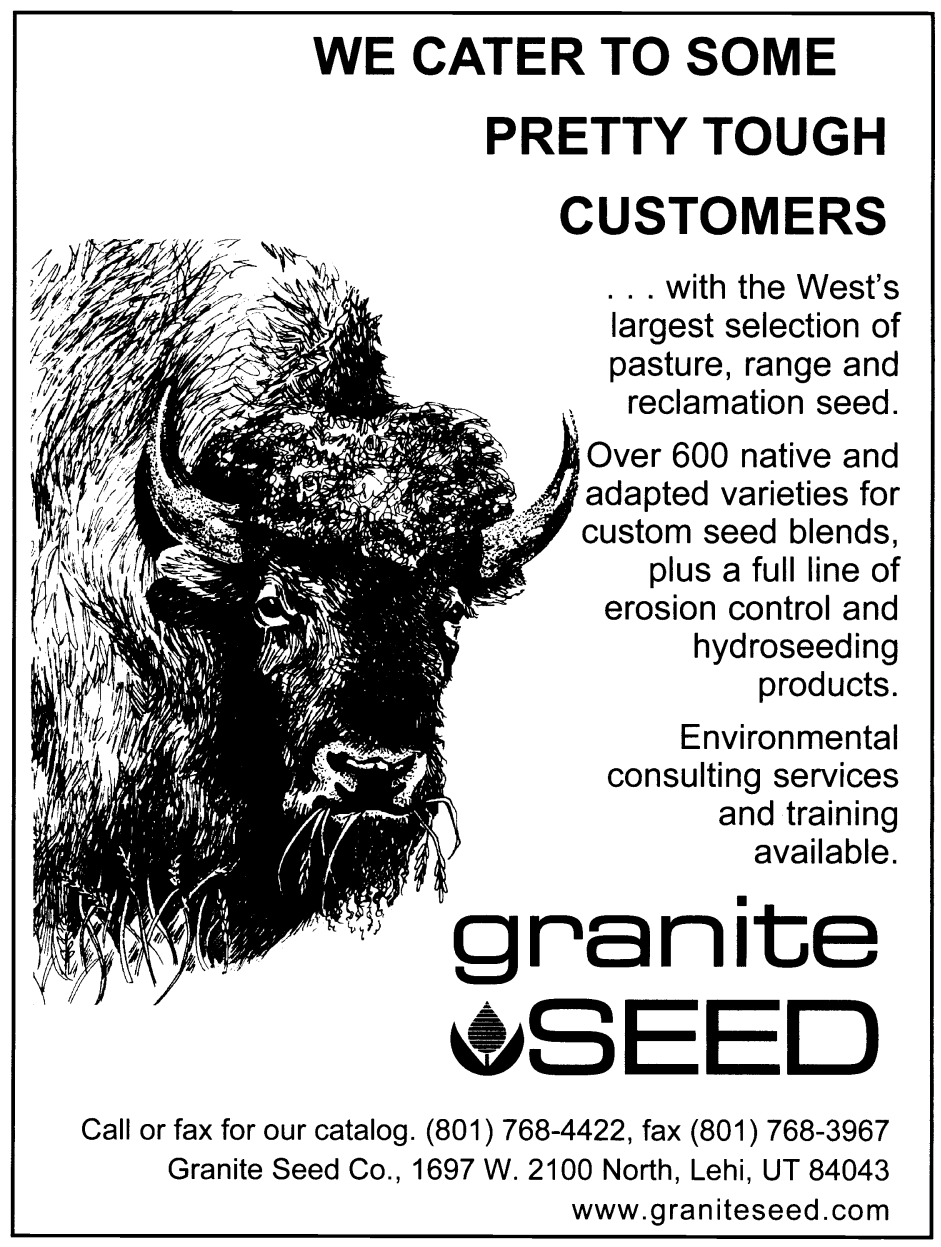

